\title{
Modified TPF Chemotherapy for Pulmonary Metastases from Squamous Cell Carcinoma of the Head and Neck
}

\author{
Takahiro Kitamura ${ }^{1)}$, Takayuki Kawashima ${ }^{1)}$, Yoshinori Koike ${ }^{1)}$, Hironori Takebayashi ${ }^{2}$, \\ Emi Maeda ${ }^{2)}$, Junpei Tanaka ${ }^{3)}$, Shirou Kosaka ${ }^{4)}$ and Osamu Semba ${ }^{1)}$
}

We report herein on 15 cases of pulmonary metastases from squamous cell carcinoma of the head and neck (SCCHN) treated with modified TPF chemotherapy (docetaxel combined with nedaplatin and 5FU). TPF chemotherapy is known as a neoajuvant chemotherapy regimen. We modified the TPF chemotherapy using nedaplatin as a substitute for cisplatin. We tried 4 courses of modified TPF chemotherapy every 3 weeks, docetaxel $60 \mathrm{mg} / \mathrm{m}^{2}$ on day 1 ; nedaplatin $75 \mathrm{mg} / \mathrm{m}^{2}$ on day 1 and 5 -FU 1000 $\mathrm{mg} /$ body by continuous infusion on days 1 to 4.11 patients received 4 courses, and the remaining of 4 patients recieved 1-3 courses because of their poor general condition. Of the 15 patients, 13 were males and 2 were females with ages ranging from 43 to 73 years (mean, 59. $1 \mathrm{yr}$ ). Two of the primary sites were in the nasopharynx, 2 in orophanrynx, 4 in the hypopharynx, 2 in the larynx and 4 in the oral cavity. Clinically there were 7 complete responders, 4 partial responders, 2 with no change, and 2 with progressive disease. The mean overall survival was 46.5 months. TPF chemotherapy may improve the overall survival.

Keywords : pulmonary metastasis, squamous cell carcinoma of the head and neck, docetaxel, nedaplatin, $5-\mathrm{FU}$

\section{References}

1）山内盛泰，力丸文秀，檜垣雄一郎，他：当科にお抢る頭頸 部扁平上皮癌の後発遠隔転移症例の検討。耳鼻と臨 55: 183-188, 2009.

2) 浅井昌大，海老原敏：遠隔転移に対する化学療法一特に肺 転移について一. JOHNS 9: 635-638, 1993.

3) Merino OR, Lindberg RD and Fletcher GH : An analysis of distant metastases from squamous cell carcinoma of the upper respiratory and digestive tracts. Cancer 40: 145-151, 1977.

4) Watanabe J, Boku H, Hashimoto M, et al. : Chemotherapy for pulmonary metastases of squamous cell carcinoma of the head and neck. Pract Otol (Kyoto) 100: 297-302, 2007.

5）内山公男, 岩㴊博史, 中山成一:頭頸部癌に対する Docetaxel, Nedaplatin, 5-Fluorouracil 3 剂併用術前化学療法臨床第I/II相 試験. 癌と化療 34: 43-48, 2007.

6）松谷 毅, 内田英二，吉田 寛，他：ネフローゼ症候群を 合併した高齢者進行食道癌に対し Docetaxel/Nedaplatin/5Fluorouracil 併用化学療法で CR が得られた 1 例. 癌と化療 38: 439-441, 2011.

7) Wang TH, Wang HS and Soong YK : Paclitaxel-induced cell death: where the cell cycle and apoptosis come together. Cancer 88: 2619-2628, 2000.

8) Judson PL, Watson JM, Gehrig PA, et al. : Cisplatin inhibits paclitaxel-induced apoptosis in cisplatin-registant ovarian cancer cell lines: possible explanation for failure of combination therapy. Cancer Res 59: 2425-2432, 1999.

9) Cerezo L, Millán I, Torre A, et al. : Prognostic factors for survival and tumor control in cervical lymph node metastases from head and neck cancer. A multivariate study of 492 cases. Cancer 69: 1224-1234, 1992.

10）小林武彦, 田原 信：がん化学療法の進歩 B. 各論 臟 器別がん治療 (6) 頭頸部がん. 化療の領域 27：1149-1157, 2011.

11）藤井正人：Head and neck cancer 頭頸部がんＩI. TPF 療 法の現状. 癌と化療 38: 1098-1102, 2011.

12）永橋立望，鈴木章之，樋口栄作，他：頭頸部癌再発症例, 肺転移症例に対する外来化学療法としての TS-1 使用効果. 頭頸部腫瘍 30：111-115, 2004.

13）犬山征夫, 木田亮紀, 佃 守, 他 : 進行 - 再発頭頸部癌 患者に対する S-1 の後期臨床第II相試験 多施設共同研究. 癌と化療 28: 1381-1390, 2001.
1) Department of Otolaryngology, Osaka Kouseinenkin Hospital

2) Department of Otolaryngology, Osaka Sailor Insurance Hospital

3) Department of Otolaryngology, Hyogo College of Medicine

4) Department of Otolaryngology, Sakibana Hospital
Corresponding Author Address : Takahiro Kitamura ent25kitamura@gmail.com 
Summary of the cases

\begin{tabular}{|c|c|c|c|c|c|c|c|c|c|}
\hline No & age, sex & origin & stage & $\begin{array}{l}\text { Months before } \\
\text { metastasis }\end{array}$ & $\begin{array}{l}\text { Number of } \\
\text { metastatic } \\
\text { tumors }\end{array}$ & $\begin{array}{l}\text { Size of the } \\
\text { metastases } \\
(\mathrm{mm})\end{array}$ & $\begin{array}{l}\text { Months after } \\
\text { metastasis }\end{array}$ & $\begin{array}{l}\text { Treatment } \\
\text { effect }\end{array}$ & outcome \\
\hline 1 & $51 \mathrm{M}$ & hypopharynx & IVB & 54 & 7 & 40 & 32 & $\mathrm{CR}$ & alive \\
\hline 2 & $71 \mathrm{M}$ & larynx & II & 41 & 1 & 20 & 24 & CR & alive \\
\hline 3 & $62 \mathrm{~F}$ & oral cavity & III & 36 & 4 & 32 & 10 & PR & alive \\
\hline 4 & $55 \mathrm{M}$ & nasopharynx & IVB & 23 & 2 & 35 & 51 & CR & $\begin{array}{l}\text { death from lung } \\
\text { metastasis }\end{array}$ \\
\hline 5 & $46 \mathrm{M}$ & nasopharynx & IVA & 18 & 8 & 15 & 29 & PR & $\begin{array}{l}\text { death from lung } \\
\text { metastasis }\end{array}$ \\
\hline 6 & $66 \mathrm{M}$ & oropharynx & IV & 9 & 5 & 40 & 8 & CR & $\begin{array}{l}\text { death from lung } \\
\text { metastasis }\end{array}$ \\
\hline 7 & $58 \mathrm{M}$ & oropharynx & II & 7 & 7 & 15 & 69 & CR & $\begin{array}{l}\text { death from other } \\
\text { diseases }\end{array}$ \\
\hline 8 & $63 \mathrm{M}$ & oral cavity & II & 11 & 2 & 15 & 7 & $\mathrm{NC}$ & $\begin{array}{l}\text { death from lung } \\
\text { metastasis }\end{array}$ \\
\hline 9 & $51 \mathrm{M}$ & oral cavity & IV & 24 & 4 & 44 & 14 & PR & $\begin{array}{l}\text { death from lung } \\
\text { metastasis }\end{array}$ \\
\hline 10 & $43 \mathrm{~F}$ & oral cavity & III & 15 & 1 & 20 & 10 & CR & $\begin{array}{l}\text { death from brain } \\
\text { metastasis }\end{array}$ \\
\hline 11 & $73 \mathrm{M}$ & hypopharynx & IVB & 37 & 5 & 80 & 12 & PD & $\begin{array}{l}\text { death from lung } \\
\text { metastasis }\end{array}$ \\
\hline 12 & $65 \mathrm{M}$ & hypopharynx & IVA & 11 & 5 & 20 & 21 & CR & $\begin{array}{l}\text { death from other } \\
\text { diseases }\end{array}$ \\
\hline 13 & $64 \mathrm{M}$ & hypopharynx & IV & 2 & 3 & 20 & 26 & PD & $\begin{array}{l}\text { death from lung } \\
\text { metastasis }\end{array}$ \\
\hline 14 & $62 \mathrm{M}$ & larynx & IVA & 34 & 2 & 13 & 35 & $\mathrm{NC}$ & $\begin{array}{l}\text { death from lung } \\
\text { metastasis }\end{array}$ \\
\hline 15 & $56 \mathrm{M}$ & unknown & & 0 & 3 & 15 & 27 & PR & $\begin{array}{l}\text { death from lung } \\
\text { metastasis }\end{array}$ \\
\hline
\end{tabular}

CR: complete response, PR: partial response, NC: no change, PD: progressive disease 